\title{
Biocatalytically active and stable cross-linked enzyme crystals of halohydrin dehalogenase HheG by protein engineering
}

Marcel Staar, ${ }^{[a]}$ Steffi Henke, ${ }^{[b]}$ Wulf Blankenfeldt, ${ }^{[b]}$ Anett Schallmey*[a]

[a] Marcel Staar, Anett Schallmey

Institute for Biochemistry, Biotechnology and Bioinformatics, Technichal University Braunschweig, Spielmannstr. 7, 38106 Braunschweig, Germany

[b] Steffi Henke, Wulf Blankenfeldt

Structure and Function of Proteins, Helmholtz Centre for Infection Research, Inhoffenstr. 7, 38124 Braunschweig, Germany

\section{* Correspondance}

Anett Schallmey, Institute for Biochemistry, Biotechnology and Bioinformatics, Technichal University Braunschweig, Spielmannstr. 7, 38106 Braunschweig, Germany.

Email: a.schallmey@tu-braunschweig.de 


\section{Abstract}

A major drawback for practical application of halohydrin dehalogenase HheG in biocatalysis is its rather low thermal stability and low organic solvent tolerance. We therefore pursued a stabilization of HheG via immobilization as cross-linked enzyme crystals. Since glutaraldehyde inactivates HheG, we introduced a cysteine residue in the crystal interface, which enabled thiol-specific cross-linking at predefined cross-linking sites. Variant HheG D114C displayed improved crystallizability and yielded stable and catalytically active CLECs using bis-maleimidoethane as cross-linker. Effective cross-linking at the predefined site could be confirmed via the CLEC crystal structure. Compared to soluble enzyme, the CLECS displayed significantly improved stability and activity at higher temperatures, lower $\mathrm{pH}$ values and in the presence of water-miscible organic solvents, which enabled their reuse over 21 days in the azidolysis of cyclohexene oxide. 


\section{$\underline{\text { Introduction }}$}

Halohydrin dehalogenases (HHDHs) (E.C. 4.5.1.-) are bacterial lyases belonging to the superfamily of short-chain dehydrogenases/reductases. While their natural function is the dehalogenation of vicinal haloalcohols with concomittant epoxide formation, ${ }^{[1]}$ they are also able to catalyze the reverse reaction, i.e. epoxide-ring opening, with a range of different nucleophiles enabling formation of $\mathrm{C}-\mathrm{C}$, $\mathrm{C}-\mathrm{N}, \mathrm{C}-\mathrm{O}$ and $\mathrm{C}-\mathrm{S}$ bonds. ${ }^{[2]}$ This has made HHDHs attractive for application in biocatalysis and various examples, e.g. for the synthesis of enantioenriched oxazolidinones, tertiary alcohols, epihalohydrines or spiroepoxyoxindoles, using $\mathrm{HHDH}$-catalysis have been reported in literature. ${ }^{[3-6]}$

Using a database mining approach based on $\mathrm{HHDH}$-specific sequence motifs, ${ }^{[7]}$ a large number of new halohydrin dehalogenases have been identified in public sequence databases in recent years ${ }^{[1]}$ and several new members have been characterized as well. ${ }^{[8]}$ While most HHDHs display similar substrate scopes, HheG from Ilumatobacter coccineus also accepts sterically more demanding cyclic epoxides as well as acyclic non-terminal epoxide substrates. ${ }^{[9,10]}$ Additionally, HheG displays $\alpha$-regioselectivity in the ring-opening of different styrene oxide derivates, ${ }^{[11]}$ whereas other HHDHs exclusively attack the $\beta$-carbon of the epoxide ring. Solving the crystal structure of $\mathrm{HheG}^{[9]}$ revealed a much broader active site for this enzyme compared to other $\mathrm{HHDHs}^{[12-15]}$ which explains the acceptance of bulkier substrates. This feature makes HheG very attractive for industrial application, e.g. for the synthesis of pharmaceutical building blocks. ${ }^{[16]} \mathrm{A}$ major drawback for application, however, is the enzyme's low stability (apparant melting temperature $\mathrm{T}_{\mathrm{m}}$ of only $38{ }^{\circ} \mathrm{C}$ ) and its low organic solvent tolerance. ${ }^{[17]}$ Based on protein engineering of HheG, variants with amino acid exchanges at position T123 have been obtained displaying up to $14 \mathrm{~K}$ higher $\mathrm{T}_{\mathrm{m}}$ as well as up to three-fold higher activity, resulting also in a slight increase in organic solvent resistance. ${ }^{[17]}$

To complement our protein engineering efforts with HheG, we herein report an orthogonal strategy to the stabilization of HheG using immobilization. ${ }^{[18]}$ Common enzyme immobilization methods include carrier binding, polymer entrapment, and carrier-free immobilization methods based on cross-linking such as cross-linked enzyme crystals (CLECs) or cross-linked enzyme aggregates (CLEAs). ${ }^{[19]}$ Since wildtype HheG crystallizes readily after a single IMAC purification step, we opted for CLEC generation to obtain an immobilized HheG preparation that would still be active at higher cosolvent concentration, and that could be reused. CLECs of various enzymes have previously been reported to display high stability regarding temperature and $\mathrm{pH}$, also in extreme conditions, and have been applied for biocatalytic reactions in non-conventional reaction media. ${ }^{[20-22]}$ The most common cross-linker used for CLEC formation is glutaraldehyde, which reacts primarily with $\varepsilon$-amino groups of lysines, but is also able to cross-link arginine and tyrosine side chains. ${ }^{[23]}$ Previous attempts, however, to cross-link HheG crystals with glutaraldehyde via soaking resulted only in inactive CLECs. The high excess of glutaraldehyde during cross-linking likely also resulted in cross-linking of Tyr165 and Arg169 of the 
catalytic triad of HheG. In contrast, cross-linking of HheG crystals with glutaraldehyde via vapor diffusion yielded CLECs that still displayed activity in the ring opening of cyclohexene oxide (1) with azide (Scheme 1). ${ }^{[24]}$ This approach, however, is impractical in larger scales where protein crystallization is generally performed in stirred vessels. ${ }^{[25]}$ Hence, we herein attempted to use protein engineering of HheG to insert desired residues in crystal contacts that would allow us to use chemoselective cross-linkers for stable CLEC generation without compromising biocatalyst activity.

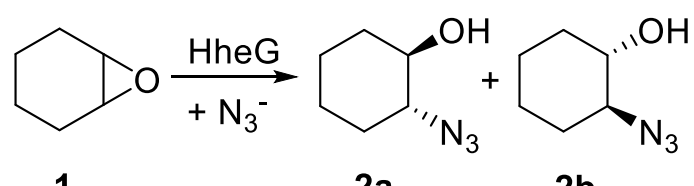

2a

$2 b$<smiles>CC([N+]#N)(c1cccc(OCC(O)CN)c1)[C@@H]1CO1</smiles>

3

4

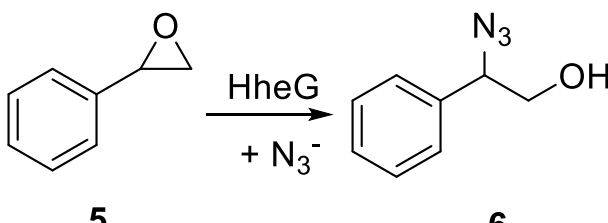

5

6

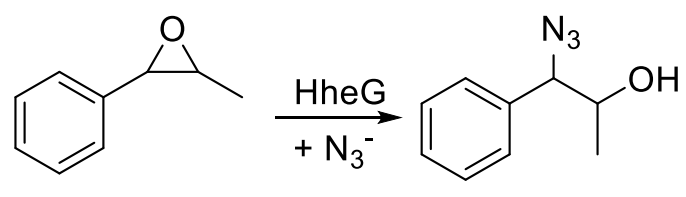

7

8<smiles>C=C(C)C1CCC2(C)OC2C1</smiles>

9<smiles>C=C(C)C1CCC(C)(O)C(N)C1</smiles>

$10 a$<smiles>C=C(C)C1CCC(C)(N)C(O)C1</smiles>

10b

Scheme 1. Epoxide ring opening reactions of HheG performed in this study [1: cyclohexene oxide, 2a: (1R,2R)-2-azido-1-cyclohexanol, 2b: (1S,2S)-2-azido-1-cyclohexanol, 3: glycidylphenylether, 4: 1-azido3-phenoxy-propan-2-ol; 5: styrene oxide, 6: 2-azido-2-phenylethanol, 7: trans-1-phenylpropylene oxide, 8: 1-azido-1-phenylpropan-2-ol, 9: (+)-cis/trans-limonene oxide, 10a: 2-azido-1-methyl-4-(prop1-en-2-yl)cyclohexan-1-ol, 10b: 2-azido-2-methyl-5-(prop-1-en-2-yl)cyclohexan-1-ol. 


\section{Results and Discussion}

\section{Crystal contact engineering}

As the previous cross-linking of HheG crystals with the commonly used cross-linker glutaraldehyde significantly reduced enzyme activity, protein engineering of HheG was used herein to introduce desired amino acids on the enzyme surface as new cross-linking sites for alternative cross-linkers. Specifically, we aimed for the insertion of cysteine residues, as HheG wild type contains only few cysteines that could potentially be cross-linked as well. Thus, the available crystal structure of wildtype $\mathrm{HheG}^{\left[{ }^{[9]}\right.}$ was analyzed for potential residues facing each other in the crystal interface. As shown in Figure 1, two major interfaces (contact points) between HheG tetramers within the crystal can be distinguished: an axial and a tangential interface. The axial interface refers to crystal contacts between tetramers lining up in infinite strings throughout the crystal, while the tangtential interface represents crystal contacts between tetramers of orthogonal strings. Existing crystal contacts were analyzed using the PRODIGY crystal webserver ${ }^{[26]}$ to identify residues with less than $5 \AA$ distance to each other. Interestingly, this revealed three residues with the same amino acid positions of different HheG tetramers facing each other in the crystal interfaces: M45 and D114 in the axial interface, and A221 in the tangential interface (Figure 1B). Those residues were selected for replacement by cysteine, as mutagenesis of one residue would directly result in the required cysteine pairs of neighbouring tetramers for later cross-linking. As the $C_{\alpha}$ distances of those opposing residues are between $6.5-8.5 \AA$ (Table S1), bis-maleimidoethane (BMOE) with a spacer length of $8 \AA$ was selected as thiol-specific crosslinker for later CLEC generation (Figure S1). ${ }^{[27]}$ 

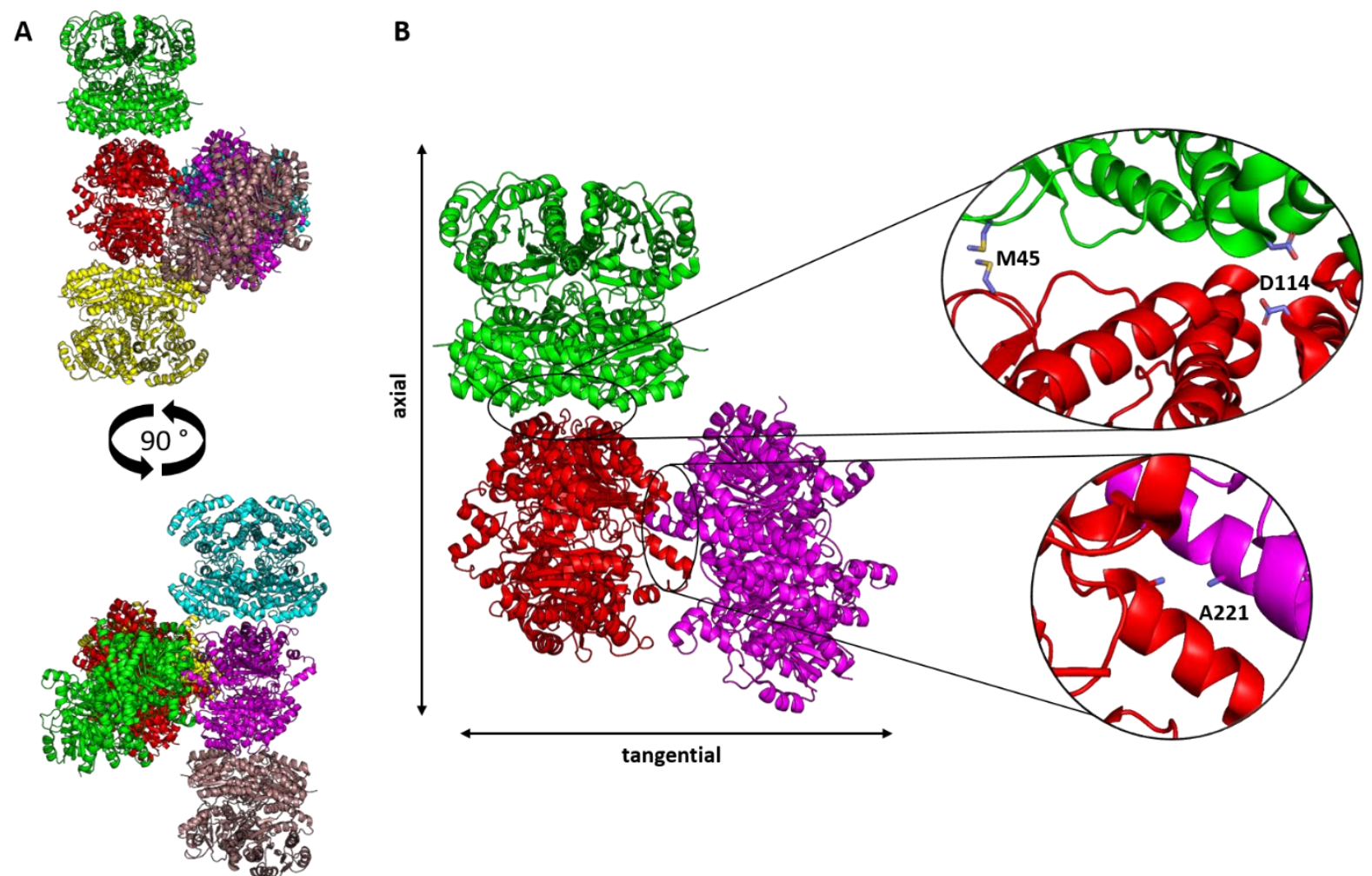

Figure 1. Crystal contact analysis of wild-type HheG (PDB ID: 5030). A) Arrangement of HheG tetramers within the unit cell; B) Axial and tangential crystal contacts of HheG with positions M45, D114 and A221 highlighted.

HheG variants M45C, D114C and A221C were generated, produced in E. coli and purified according to established protocols for wild-type HheG. Corresponding yields after purification are listed in Table 1. Before crystallization and cross-linking, these mutants were characterized regarding their specific activity, enantioselectivity and thermal stability for comparison with the wild-type enzyme (Table 1).

Table 1. Specific activities and product enantiomeric excess (ee $)$ in the conversion of cyclohexene oxide (1) with azide as nucleophile, as well as melting temperatures $\left(T_{m}\right)$ of HheG wild type and respective variants applied as soluble enzymes. Specific activity and product enantiomeric excess (ee ${ }_{\mathrm{p}}$ ) were determined based on duplicate measurements, apparent melting temperatures $\left(T_{m}\right)$ where obtained from triplicate measurements.

\begin{tabular}{lllll}
\hline Variant & Yield $[\mathrm{mg} / \mathrm{I}]$ & $\begin{array}{l}\text { Specific activity } \\
{[\mathrm{U} / \mathrm{mg}]}\end{array}$ & ee $_{\mathrm{p}}[\%]$ & $\mathrm{T}_{\mathrm{m}}\left[{ }^{\circ} \mathrm{C}\right]$ \\
\hline WT & 204 & $2.32 \pm 0.3$ & $49.1 \pm 0.1$ & $41 \pm 0.1$ \\
\hline M45C & 22 & $1.41 \pm 0.01$ & $65.4 \pm 0.1$ & $42.5 \pm 0.2$ \\
\hline D114C & 130 & $2.35 \pm 0.05$ & $49.9 \pm 0.5$ & $40.5 \pm 0.2$ \\
\hline A221C & 190 & $1.79 \pm 0.1$ & $49.5 \pm 0.8$ & $40 \pm 0.1$ \\
\hline
\end{tabular}


${ }^{a}$ Reaction conditions: $20 \mathrm{mM}$ cyclohexene oxide (1), $40 \mathrm{mM}$ azide and $50 \mu \mathrm{g}$ enzyme in $1.5 \mathrm{ml} 50 \mathrm{mM}$ Tris $\cdot \mathrm{SO}_{4}, \mathrm{pH} 7.0$ at $22{ }^{\circ} \mathrm{C}$ and $900 \mathrm{rpm}$

This analysis revealed a similar activity and enantioselectivity of HheG D114C for formation of azidoalcohol $\mathbf{2} \mathbf{b}$ and a similar melting temperature $\left(T_{m}\right)$ as determined for Hhe G wild type. In contrast, variant M45C displayed significantly reduced specific activity, while product $\mathbf{2} \mathbf{b}$ was obtained with higher enantiomeric excess. As replacement of M45 by cysteine significantly altered the biochemical characteristics of this variant compared to wild-type HheG, this variant was not investigated further. The specific activity of HheG A221C was also reduced (75\% of wild-type activity), whereas product enantiomeric excess and $T_{m}$ were similar to that of HheG wild type. Since HheG A221C was the only variant with a cysteine pair for cross-linking in the tangential crystal interface, this variant was included in further studies, despite its slightly reduced specific activity. Both variants, D114C and A221C, as well as wild-type HheG, were further compared regarding their crystallization properties.

\section{Crystallization and cross-linking}

Crystallization of HheG wild type had previously been demonstrated using $10 \%$ (w/v) PEG4000 as precipitant, HEPES buffer with a pH of 7.3 to 7.5 and protein concentrations between 6 and $32 \mathrm{mg} / \mathrm{ml} .{ }^{[24,28]}$ Hence, similar conditions were used to investigate the crystallizability of variants D114C and A221C (see supplementary for more details). This revealed that variant D114C displayed a higher crystallizability and required less PEG4000 compared to HheG wild type, while no crystals could be obtained for variant A221C (Table S2). Moreover, variant D114C still gave the same hexagonal-shaped crystals as wild-type HheG (Figure S2), but crystallized faster (Figure S3) and formed overall larger crystals (Figure S4). As the space group and cell parameters of D114C crystals were found to be the same or very similar to that of wild-type HheG (see below), the mutation at position 114 is likely responsible for improved crystallizability of variant D114C. In wild-type HheG, always two D114 residues of opposing tetramers face each other in the axial crystal interface, most likely resulting in a slight repulsion of the charged carboxyl side chains during crystallization. In contrast, the thiols in variant $\mathrm{D} 114 \mathrm{C}$ (cysteine $\mathrm{p} K_{\mathrm{a}}=8.1$ ) are only partially charged at the $\mathrm{pH}$ used for crystallization. Moreover, mutation D114C might result in a lower conformational entropy of the amino acid side chains at position 114 , which would also contribute to improved protein crystallization. ${ }^{[29,30]}$

After crystallization of HheG wild type and D114C at $20 \mu \mathrm{l}$ scale, cross-linking of both variants with the cysteine-specific cross-linker BMOE was tested. As expected, crystals of HheG wild type incubated with $2 \mathrm{mM} \mathrm{BMOE}$ for $24 \mathrm{~h}$ re-dissolved within $72 \mathrm{~h}$ after transfer into reaction buffer (Figure S5). In contrast, respective crystals of HheG $\mathrm{D} 114 \mathrm{C}$ did not re-dissolve after cross-linking with $2 \mathrm{mM}$ BMOE for $24 \mathrm{~h}$ 
(Figure S6). This indicates that only HheG D114C crystals offer suitable cross-linking sites for stable cross-linking with BMOE.

For the stable CLECs, the activity in the conversion of cyclohexene oxide (1) with azide was subsequently examined and compared to soluble enzyme preparations (Figure 2). As mentioned previously, CLECs of HheG wild type cross-linked with glutaraldehyde via soaking displayed only negligible residual activity in the range of the chemical background. In contrast, HheG D114C CLECS cross-linked with BMOE via soaking displayed high conversion in the azidolysis of 1 , albeit at $4 \mathrm{~h}$ reaction time conversion is slightly lower compared to the soluble enzyme (Figure 2). The latter, however, might be due to diffusion limitations within the crystal, ${ }^{[24,31]}$ reducing substrate accessibility and product release. On the other hand, the limited enzyme motion within the CLEC could also explain the observed activity decrease.

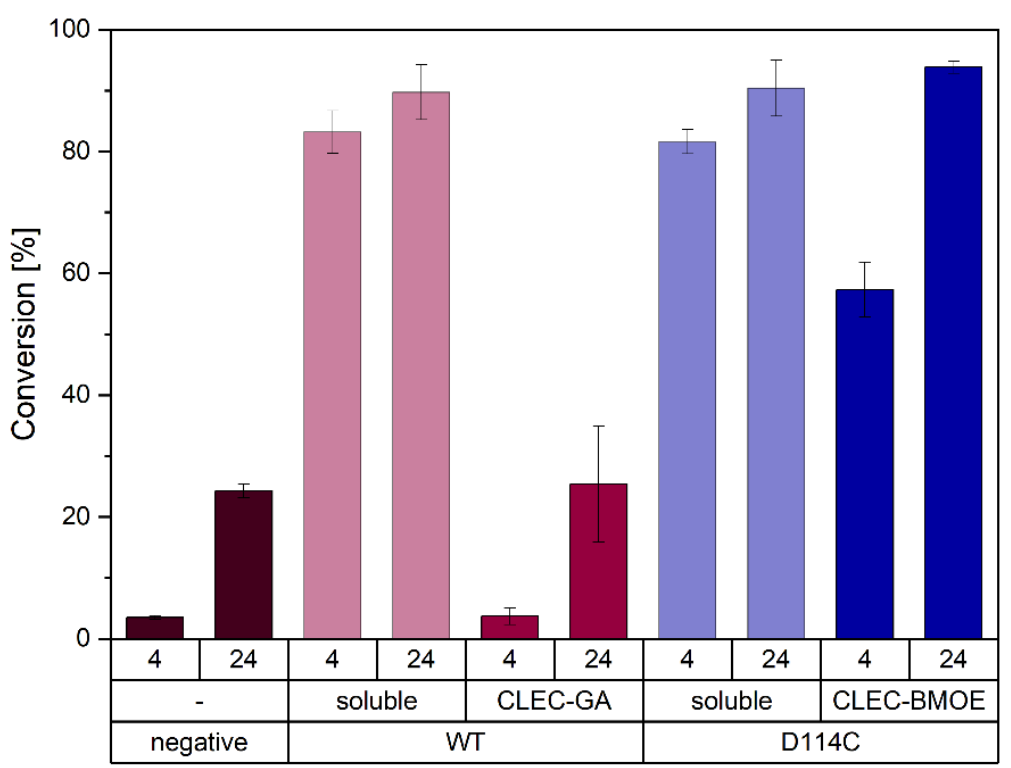

Figure 2. Conversion of $20 \mathrm{mM}$ cyclohexene oxide (1) with $40 \mathrm{mM}$ azide using HheG WT and mutant D114C (each $100 \mu \mathrm{g}$ ) in soluble or CLEC form after 4 and $24 \mathrm{~h}$ of reaction [GA: glutaraldehyde]. "Negative" represents the chemical background reaction without enzyme addition. Error bars indicate standard deviations from five parallel reactions.

Literature reports indicated that cross-linking can also have a positive effect on the enantioselectivity of an enzyme. ${ }^{[32]}$ Thus, the enantioselectivity of our CLECs in the conversion of $\mathbf{1}$ was investigated as well. Interestingly, HheG D114C CLECs formed azidoalcohol 2 with slightly higher product enantiomeric excess than the respective soluble enzyme ( $56.0 \%$ vs $49.9 \%$, respectively). This might be explained by reduced molecular motion of enzyme molecules within the crystal due to cross-linking. ${ }^{[33]}$ Moreover, an $8 \mathrm{~K}$ increase in apparent melting temperature $\left(\mathrm{T}_{\mathrm{m}}\right)$ compared to soluble enzyme was observed for D114C CLECs cross-linked with BMOE (Figure S7). This gain in melting temperature was 
also obtained when using only $0.5 \mathrm{mM} \mathrm{BMOE}$ and a cross-linking time of $24 \mathrm{~h}$, as well as with $2 \mathrm{mM}$ $\mathrm{BMOE}$ and $3 \mathrm{~h}$ cross-linking time (Figure $\mathrm{S} 8$ ). This demonstrates the effectiveness of BMOE as crosslinker for HheG D114C crystals. Using higher cross-linker concentrations or longer cross-linking times did not enhance CLEC stability further (Figure S8). For comparison, cross-linking of wild-type HheG crystals with glutaraldehyde yielded a $T_{m}$ increase by $9 \mathrm{~K}$ (data not shown).

\section{Crystal structure of HheG D114C CLEC}

To confirm effective cross-linking of HheG D114C crystals with BMOE, the crystal structure of respective CLECs was solved at $2.7 \AA ̊$ resolution (PDB-ID: 7QY3). Variant D114C crystallized in the same trigonal space group $P 3_{1} 21$ as wild-type HheG. ${ }^{[9]}$ Moreover, unit cell parameters were also similar to that of the wild-type enzyme (Table S3). Analysis via PDBePISA webserver ${ }^{[34]}$ confirmed that crystals of variant D114C exhibited the same crystal contacts (axial and tangential interface, see Figure 1) as wildtype HheG except for the mutated residue 114, where an aspartic acid was exchanged by a cysteine. In an overlay of both structures (Figure 3A), residue 114 - either aspartic acid in wild-type HheG or cysteine in variant $\mathrm{D} 114 \mathrm{C}$ - adopts the same position and conformation.

As can be seen in Figure 3C, additional electron density between cysteines at position 114, facing each other in the crystal contact, is present in the HheG D114C structure. The shape and size of this additional electron density fit to that of the cross-linker BMOE, confirming effective cross-linking at the desired position. This extra density can be found for every cysteine 114 within the asymmetric unit, suggesting a high degree of cross-linking with BMOE for HheG D114C CLECs. Interestingly, there is no previous literature precedent, where cross-links within a biocatalytic CLEC could be visualized. This is explained by the fact that previously glutaraldehyde has been used almost exclusively as cross-linker for CLEC generation. ${ }^{[35]}$ As mentioned before, glutaraldehyde is able to react with different amino acids within a protein and is further prone to polymerization. This results in a multitude of cross-linking possibilities that will be occupied only randomly within a CLEC, hampering visualization by X-ray crystallography. ${ }^{[36,37]}$ In contrast, our approach yields highly defined cross-linking sites for stable CLEC generation and, thus, permits also visualization of resulting cross-links. 
A

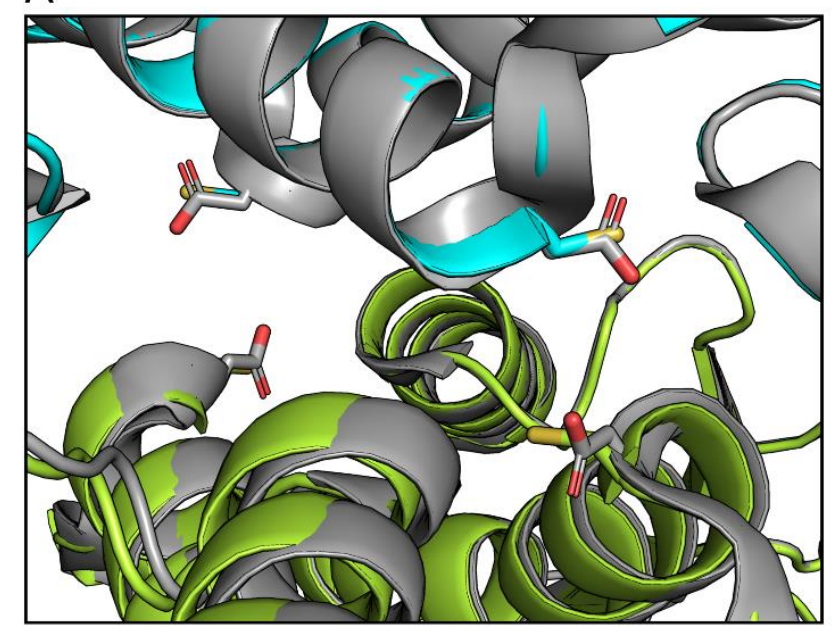

C

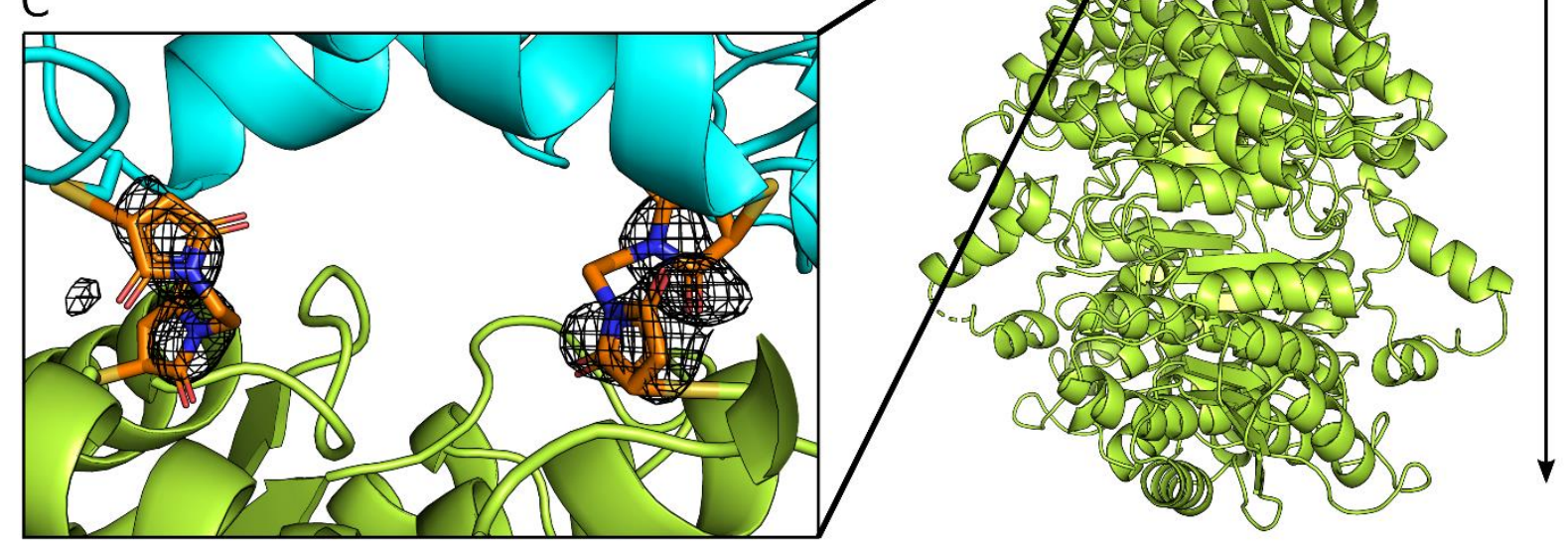

B

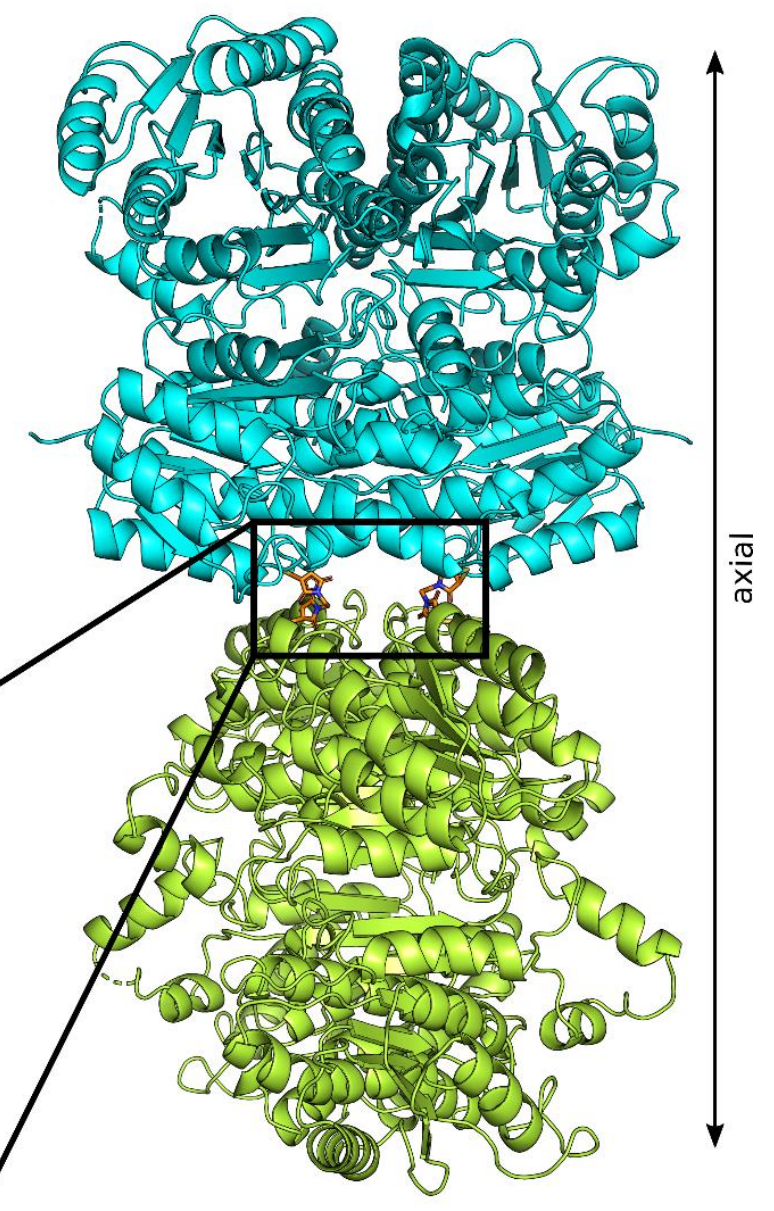

Figure 3. Crystal structure of HheG D114C. A) Overlay of residue 114 of variant HheG D114C (colored) and the wild-type structure (gray). B) Cross-linked chains of neighboring tetramers in axial orientation, BMOE shown in orange. C) Magnified view of the bound cross-linker BMOE fitting into the respective

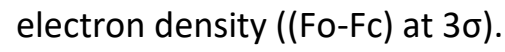

\section{Further CLEC characterization}

As a higher melting temperature has been observed for HheG D114C CLECs cross-linked with BMOE, we further investigated the temperature and pH profile of such CLECs. In line with the observed higher $T_{m}$, HheG D114C CLECs displayed their highest relative activity at $40^{\circ} \mathrm{C}$ in the azidolysis of 1 , while highest relative activity of soluble enzyme was obtained at $25^{\circ} \mathrm{C}$ (Figure $4 \mathrm{~A}$ ). Moreover, also the determined $T_{50}$ value of HheG D114C CLECs was $12 \mathrm{~K}$ higher compared to soluble enzyme (Figure S9), further confirming an increased thermal stability upon CLEC formation.

Interestingly, the $\mathrm{pH}$ profile of the CLECs broadened compared to soluble enzyme, specifically with respect to performance at lower $\mathrm{pH}$ values, while the $\mathrm{pH}$ optimum stayed at $\mathrm{pH}=6$ (Figure 4B). This $\mathrm{pH}$ optimum is in line with the catalytic mechanism of HHDHs for epoxide ring opening, with Tyr165 of the catalytic triad donating a proton to the oxyanion generated during epoxide ring opening. ${ }^{[9]}$ While acidic 
$\mathrm{pH}$ will facilitate reprotonation of Tyr165 for the next catalytic cycle, the enzyme is inactivated at low $\mathrm{pH}$ values (Figure 4B). The latter is accompanied by a reduced enzyme stability at acidic $\mathrm{pH}$, which was partially mitigated by cross-linking. In line with these results, CLECs exhibited also significantly higher $\mathrm{T}_{\mathrm{m}}$ values at lower $\mathrm{pH}$ compared to soluble enzyme (Figure $\mathrm{S} 10$ ).
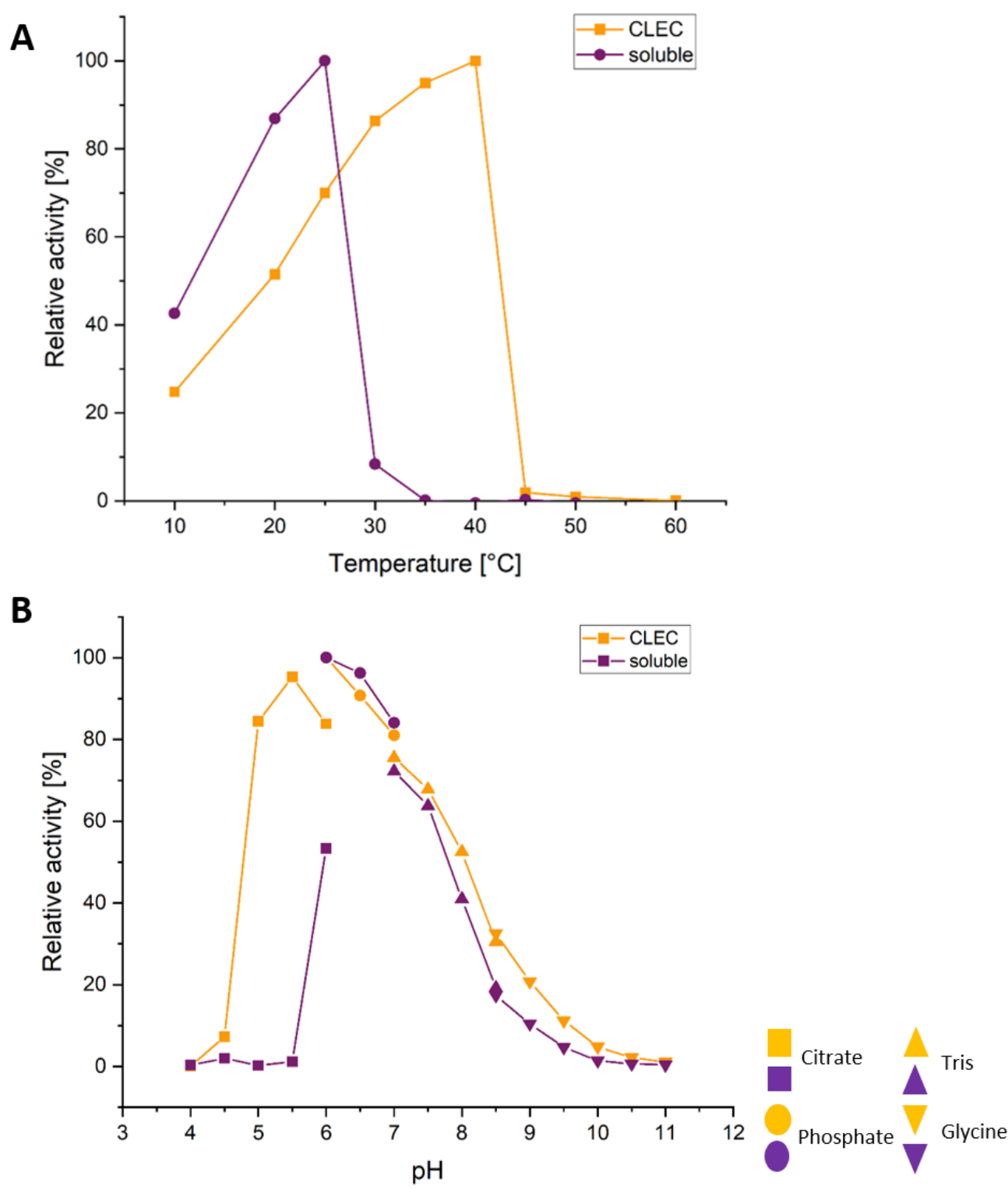

Figure 4. Temperature (A) and pH (B) profiles of HheG D114C CLECs (black) in comparison to soluble enzyme (red) in the conversion of $20 \mathrm{mM}$ cyclohexene oxide (1) with $40 \mathrm{mM}$ azide at $22^{\circ} \mathrm{C}$ using each $100 \mu \mathrm{g}$ of enzyme. Relative activities have been calculated by setting the highest conversion to $100 \%$ activity. For temperature profile $100 \%$ relative activity corresponds to $64.1 \%$ (soluble) or $48.3 \%$ (CLEC) conversion. For $\mathrm{pH}$ profile $100 \%$ relative activity corresponds to $85.5 \%$ (soluble) or $71.4 \%$ (CLEC) conversion. 
Previous literature on cross-linked enzyme crystals of Candida rugosa lipase and Pseudomonas cepacia lipase, as well as CLECs of the protease subtilisin reported improved activity and stability of respective CLECs in organic solvents compared to souble enzymes. ${ }^{[20,21]}$ Organic co-solvents are usually required to increase substrate solubility in HHDH-catalyzed reactions. Previously, however, significantly reduced activity/stability of HheG in the presence of different water-miscible organic solvents has been observed. ${ }^{[17]}$ Hence, we also investigated the activity of HheG D114C CLECs in the presence of $25 \%$ $(\mathrm{v} / \mathrm{v})$ of various co-solvents. In comparison to soluble enzyme, D114C CLECs were still active in the presence of $25 \%(\mathrm{v} / \mathrm{v}) \mathrm{DMF}$, methanol, ethanol and isopropanol, whereas soluble enzyme seemed to be fully inactivated at this solvent concentration (Figure 5). In contrast, the achieved conversion of soluble HheG D114C in the presence of $25 \%(\mathrm{v} / \mathrm{v})$ DMSO for the azidolysis of 1 was similar to the respective conversion obtained with the CLECs, while for both enzyme preparations no activity could be observed with $25 \%(\mathrm{v} / \mathrm{v})$ acetonitrile. Moreover, melting temperatures of HheG D114C CLECs and soluble enzyme in the presence of $10 \%(\mathrm{v} / \mathrm{v})$ co-solvents have been determined (Table S4), which clearly indicate that acetonitrile has the highest destabilizing effect on both enzyme preparations. In contrast, the influence of DMSO on D114C stability (soluble and CLEC form) seems only marginal. Both results are in line with obtained conversion data (Figure 5). According to $T_{m}$ measurements, D114C CLECs are more stable in the presence of $10 \%(\mathrm{v} / \mathrm{v})$ organic co-solvent compared to soluble enzyme for all co-solvents tested (Table S4), again confirming their higher overall stability.

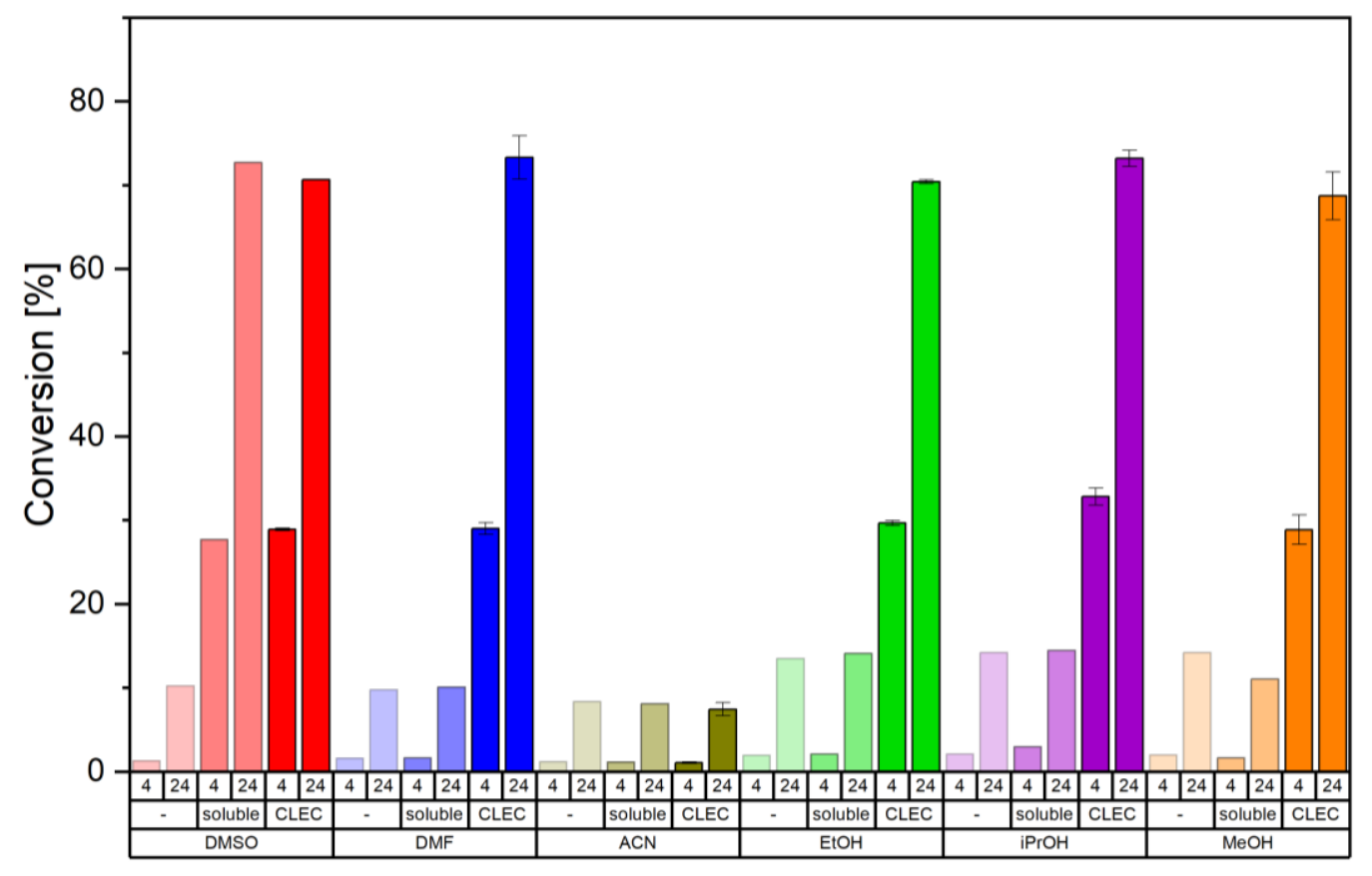

Figure 5. Influence of $25 \%(\mathrm{v} / \mathrm{v})$ co-solvent on HheG D114C CLECs and soluble enzyme in the conversion of $20 \mathrm{mM}$ cyclohexene oxide (1) with $40 \mathrm{mM}$ azide at $22^{\circ} \mathrm{C}$ using each $100 \mu \mathrm{g}$ enzyme. Used co-solvents: dimethyl sulfoxide (DMSO), dimethyl formamide (DMF), acetonitrile ( $A C N)$, ethanol (EtOH), 
isopropanol ( $\mathrm{iPrOH})$ and methanol (MeOH). Samples were taken after 4 and 24 h. "-“ indicates negative control reactions without enzyme addition. All reactions were performed in duplicate.

The observed higher stability of D114C CLECs in the presence of organic co-solvents enabled also the use of significantly higher substrate concentrations in the azidolysis of 1. Specifically, D114C CLECs were still active at the highest substrate concentration tested (200 mM 1 at $20 \%$ (v/v) isopropanol), while soluble enzyme was fully inactive already (Figure S11). This result further confirms the significantly increased stability of D114C CLECs in the presence of water-miscible organic solvents.

To evaluate also long-term stability of our CLECs at the used reaction temperature $\left(22^{\circ} \mathrm{C}\right)$, half-life times $\left(t_{1 / 2}\right)$ of soluble enzyme and CLECs of HheG D114C were investigated. To facilitate the determination of $t_{1 / 2}$ at $22^{\circ} \mathrm{C}$, deactivation rate constants $k_{d}$ of soluble enzyme and CLECs at higher temperatures $\left(>30^{\circ} \mathrm{C}\right)$ were determined. Using the Eyring equation ${ }^{[38]}$, respective deactivation rate constants at $22^{\circ} \mathrm{C}$ could be extrapolated (Figure S12), and deactivation energies as well as half-life times were determined (Table S6). As a result, a half-life time of 64 days at $22^{\circ} \mathrm{C}$ was obtained for D114C CLECs, which is consistent with our reusability data (see below). In contrast, the respective $t_{1 / 2}$ of soluble enzyme at $22^{\circ} \mathrm{C}$ is only $21 \mathrm{~h}$. Hence, D114C CLECs exhibit a more than 60 times higher half life than soluble HheG D114C. Similar increases in half life upon CLEC formation have also been reported for other enzymes. ${ }^{[39,40]}$ Likewise, more energy is required for the deactivation of HheG D114C CLECs $(46.8 \mathrm{~kJ} / \mathrm{mol})$ in comparison to soluble enzyme $(36.3 \mathrm{~kJ} / \mathrm{mol})$, underlining once more the significant gain in stability upon cross-linking.

\section{Application of HheG D114C CLECs in biocatalytic reactions}

Apart from higher stability, immobilization of an enzyme as CLEC also offers the advantage of easy enzyme recovery from a product stream ${ }^{[35]}$ and reuse in biocatalytic reactions. Therefore, repeated batch reactions with cyclohexene oxide (1) and azide at $22^{\circ} \mathrm{C}$ were performed for each $24 \mathrm{~h}$ with daily reuse of D114C CLECs over a total of 21 days. After each reaction, the CLECs were separated by centrifugation before reuse in a new batch reaction. As shown in Figure 6, D114C CLECs displayed activity over all reaction cycles, obtaining still $87 \%$ and $70 \%$ of the initially observed conversion after 5 and 21 days, respectively. The observed sligth decrease in enantiomeric excess during this time span can be explained by a stronger influence of the chemical background reaction with decreasing enzyme activity. Microscopic analysis of the D114C CLECs after the 21 reaction cycles confirmed that they retained their hexagonal shape with sizes of about $100 \mu \mathrm{m}$ (Figure S13). 


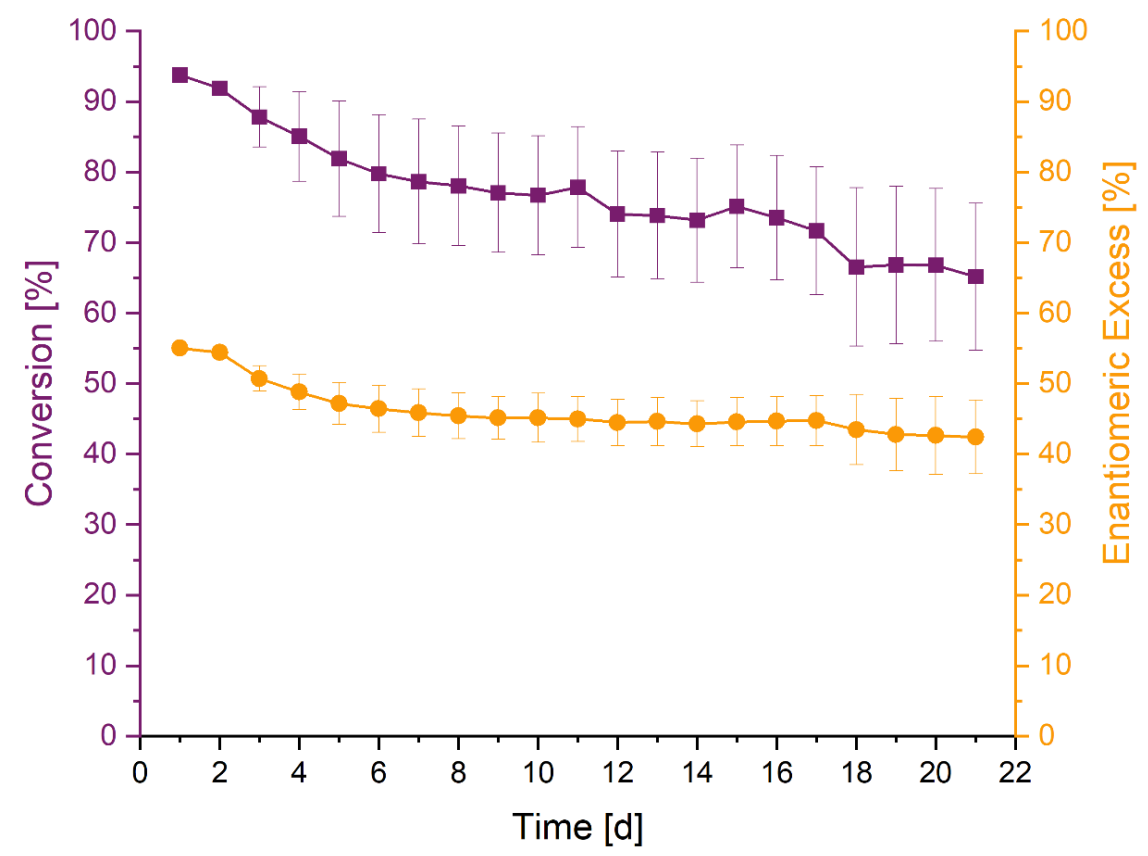

Figure 6. Repetitive batch reactions with cyclohexene oxide (1) and azide at $22^{\circ} \mathrm{C}$ with reuse of HheG D114C CLECs. Each reaction cycle (24 h) contained $100 \mu \mathrm{g}$ CLECs, 20 mM cyclohexene oxide (1) and 40 $\mathrm{mM}$ azide in a total of $1 \mathrm{~mL}$. After $24 \mathrm{~h}$ of reaction, the CLECs were centrifuged, the supernatant was removed and fresh reaction media including the substrates was added to start a new cycle. Standard deviations are based on quintuple measurements. For comparison, chemical background conversion in this reaction (one cycle) without enzyme addition reached $24 \%$.

In addition to cyclohexene oxide, we also tested the application and reuse of D114C CLECs in the azidolysis of phenylglycidylether $(3)^{[8]}$, styrene oxide $(5)^{[11]}$, phenylpropylene oxide $(7)^{[10]}$ and limonene oxide $(9)^{[9]}$, which had been demonstrated previously to be converted by HheG. Daily reuse of D114C CLECS over 5 cycles yielded no or only a slight decrease in conversion with these four epoxide substrates (Figure S14). The activity recovery comparing conversion in the first and fifth cycle was 99.4\% (3), 100\% (5), 93.9\% (7) and 91.1\% (9). In comparison, CLEAs of HheC from Agrobacterium radiobacter AD1 displayed an activity recovery of $74 \%$ after 10 reaction cycles of each $30 \mathrm{~min}$ in the conversion of $5 \mathrm{mM}$ 1,3-dichloro-2-propanol. ${ }^{[41]}$ Hence, our data demonstrate the effectiveness of HheG immobilization via CLEC formation to obtain a stable and reusable biocatalyst.

Additionally, storage stability of D114C CLECs at $8^{\circ} \mathrm{C}$ was investigated yielding $98.7 \%$ residual activity after 1 week and $83.3 \%$ after 1 month of storage.

\section{Conclusion}

In conclusion, we employed crystal contact engineering to generate CLECS of HheG with chemoselective cross-linking at predefined cross-linking sites. To this end, HheG variant D114C was generated 
for stable cross-linking with the thiol-specific cross-linker BMOE. In contrast to CLECs generated with the commonly used cross-linker glutaraldehyde, this approach yielded selective cross-linking at welldefined sites without compromising enzyme activity. The resulting CLECs not only displayed significantly higher stability regarding temperature, $\mathrm{pH}$ and co-solvent concentrations compared to the soluble enzyme, but also enabled the repetitive use of HheG in the azidolysis of various epoxide substrates (up to 21 days as shown for the conversion of cyclohexene oxide). Overall, those CLECS represent an important first step towards a potential future application of HheG in industrial settings. Furthermore, the cross-linking approach described herein can be easily transferred to other biocatalysts with high crystallizability that would typically be inactivated upon cross-linking with glutaraldehyde. Building on the variety of commercially available mono- and bi-specific crosslinkers, this approach should further allow crosslinking beyond the thiol functionality. Even the use of cleavable cross-linkers is conceivable, opening up a whole range of new possibilities for furture applications.

\section{Experimental Section}

\section{Chemicals}

Substrates cyclohexene oxide (1) and styrene oxide (5) were purchased from Thermo Fisher Scientific (Geel, Belgium). Substrates phenylglycidylether (3), phenylpropylene oxide (7) and limonene oxide (9) were purchased from Merck (Darmstadt, Germany). All chemicals were of highest available purity.

\section{Bacterial strains and plasmids}

E. coli DH5 $\alpha$ was used for cloning and other genetic manipulations whereas E. coli BL21(DE3) Gold was used for heterologous protein production as outlined before. ${ }^{[8]}$ Further, expression vector pET-28a(+) (Merck) was used to clone respective genes under control of the T7 promoter while adding an $\mathrm{N}$ terminal $\mathrm{His}_{6}$-tag to heterologously produced proteins.

\section{HheG engineering}

Amino acid positions were selected based on their position at the crystal interface. Symmetry mates of HheG were generated using PyMOL (version 2.3.3, Schrödinger, New York, NY, United States). This way, amino acids facing each other within a distance of less than $5 \AA$ at the crystal interface were selected by the PRODIGY crystal webserver. ${ }^{[26]}$ Site-directed mutagenesis was performed using the PfuUltra II Hotstart PCR Mastermix (Agilent Technologies, Santa-Clara, CA, United States). Forward and reverse mutagenic primers (Table 2) were designed with PrimerX (Carlo Lapid, 2003, http://bioinformatics.org/primerx/index.htm), purchased from Merck and used in concentrations of $0.25 \mu \mathrm{M}$ each with $100 \mathrm{ng}$ of $\mathrm{pET} 28 \mathrm{a}(+)-h h e G$ template. ${ }^{[17]}$ Otherwise, the mutagenesis protocol was in agreement with the manufacturer's instructions. 
Table 2. Mutagenic primers used in this study. Base exchanges are shown in bold.

\begin{tabular}{ll}
\hline Mutagenic primer & Sequence 5'-3' $^{\prime}$ \\
\hline f_hheG_M45C & CAGCCGGTGATGGCACCTGCGTTGGTGTTGAAGAAAG \\
\hline r_hheG_M45C & CTTTCTTCAACACCAACGCAGGTGCCATCACCGGCTG \\
\hline f_hheG_D114C & CGGCAAATTTCTGGATATGACCTGCGATCAGTGGGCAAAAGTTAAAG \\
\hline r_hheG_D114C & CTTTAACTTTTGCCCACTGATCGCAGGTCATATCCAGAAATTTGCCG \\
\hline f_hheG_A221C & CGTCGTGCAATGATTGAATGCCAGGTTCCGCTGCGTCG \\
\hline r_hheG_A221C & CGACGCAGCGGAACCTGGCATTCAATCATTGCACGACG \\
\hline
\end{tabular}

\section{Protein production and purification}

Hhe and its variants were produced in $500 \mathrm{ml}$ Terrifc Broth (TB) (per liter: $4 \mathrm{ml}$ glycerol, $12 \mathrm{~g}$ peptone, $24 \mathrm{~g}$ yeast extract, $0.17 \mathrm{M} \mathrm{KH}_{2} \mathrm{PO}_{4}, 0.74 \mathrm{M} \mathrm{K}_{2} \mathrm{HPO}_{4}$ ) supplemented with $50 \mathrm{\mu g} / \mathrm{ml}$ kanamycine. Further, $50 \mathrm{ml}$ of an overnight culture in induction, and $0.2 \mathrm{mM}$ Isopropyl- $\beta$-D-thiogalactopyranosid (IPTG) was inoculated with $10 \%(\mathrm{v} / \mathrm{v})$ preculture. In detail, protein expression was initiated by adding $50 \mathrm{ml}$ of an overnight preculture (grown at $37{ }^{\circ} \mathrm{C}$ in LB medium) and $0.2 \mathrm{mM} \mathrm{IPTG} .{ }^{[9]}$ Then, cultivation in shake flasks was performed for $24 \mathrm{~h}$ at $22^{\circ} \mathrm{C}$ and $220 \mathrm{rpm}$ before cell pellets were collected by centrifugation (20 min, $3494 \mathrm{~g}, 4^{\circ} \mathrm{C}$ ) and stored at $-20^{\circ} \mathrm{C}$ until further purification.

For cell disruption, cell pellets were first resuspended in $30 \mathrm{ml}$ buffer A (50 mM Tris-5O $\mathrm{SO}_{4}, 300 \mathrm{mM}$ $\mathrm{Na}_{2} \mathrm{SO}_{4}, 25 \mathrm{mM}$ imidazole, $\mathrm{pH}$ 7.9), supplemented with $1 \mathrm{mg} / \mathrm{ml}$ lysozyme and 1 Pierce Protease Inhibitor Mini Tablet (EDTA-free, Life Technologies, Thermo Fisher Scientific), and then subjected to ultrasound sonification on ice for $7 \mathrm{~min}$ (cycle: $10 \mathrm{~s}$ pulse, $20 \mathrm{~s}$ pause). After sonification, cell free extracts were generated by collecting the supernatant after centrifugation $\left(45 \mathrm{~min}, 18000 \mathrm{~g}, 4^{\circ} \mathrm{C}\right.$ ) and subsequent filtration through a syringe filter ( $0.45 \mu \mathrm{m}$ pore diameter).

Cell free extracts were loaded ( $2 \mathrm{ml} / \mathrm{min}$ flow rate) on a $5 \mathrm{ml}$ HisTrap FF column (GE Healthcare, Freiburg, Germany), pre-equlibrated with buffer A using an ÄktaStart FPLC system (GE Healthcare). After loading, the column was washed with 10 column volumes of buffer $A$ to remove other proteins. For the elution of $\mathrm{His}_{6}$-tagged target proteins, a gradient over $60 \mathrm{ml}$ to $100 \%$ buffer B $\left(50 \mathrm{mM}\right.$ Tris-SO${ }_{4}$, $300 \mathrm{mM} \mathrm{Na}_{2} \mathrm{SO}_{4}, 500 \mathrm{mM}$ imidazole, $\mathrm{pH}$ 7.9) was used to collect $1 \mathrm{ml}$ fractions. For desalting, fractions with highest UV absorbance were first pooled and then loaded in portions of $15 \mathrm{ml}$ onto an HiPrep 26/10 desalting columns (GE Healthcare), pre-equilibrated with TE buffer ( $10 \mathrm{mM}$ Tris·SO ${ }_{4}, 4 \mathrm{mM}$ EDTA, $\mathrm{pH} 7.9,10 \%(\mathrm{v} / \mathrm{v})$ glycerol). Subsequently, proteins of interest were eluted in TE-buffer and $5 \mathrm{ml}$ fractions. Fractions with highest UV absorbance were concentrated using Vivaspin Turbo 15 centrifugation units (Sartorius, Göttingen, Germany) with 10 kDa molecular weight cut-off. Protein concentrations were calculated by measuring absorbances at $280 \mathrm{~nm}$ using a NP80 nanophotometer 
(Implen, München, Germany) via Lambert-Beer law with molar extinction coefficients and molecular weights obtained from Protparam ${ }^{[42]}$. For variants with extra cysteine substitutions, $5 \mathrm{mM} \beta$-mercapto ethanol were added to purification buffers and $5 \mathrm{mM}$ dithiotreitol to storage buffer.

\section{Activity and enantioselectivity determination}

To determine specific activities of HheG and its variants, conversions of $20 \mathrm{mM}$ cyclohexene oxide (1) with $40 \mathrm{mM}$ sodium azide were investigated in $1.5 \mathrm{ml}$ reaction volumes in $50 \mathrm{mM}$ Tris. $\mathrm{SO}_{4}, \mathrm{pH} 7.0$ at $22^{\circ} \mathrm{C}$ (900 rpm in Eppendorf ThermoMixer C). After starting reactions by addition of $50 \mu \mathrm{g}$ enzyme, samples were taken after 1, 3, 5, 10, 15, 30, and $60 \mathrm{~min}$ and extracted with an equal volume of tertbutyl methyl ether (TBME) containing $0.1 \%(\mathrm{v} / \mathrm{v}) n$-dodecane. Organic phases were dried over $\mathrm{MgSO}_{4}$ and samples were analyzed by achiral GC (Table S7). ${ }^{\left[{ }^{9]}\right.}$

When measuring the conversion of CLECs and comparison to soluble enzyme, reactions were performed similarly but this time in $1 \mathrm{ml}$ reaction volumes with $100 \mu \mathrm{g}$ biocatalyst. To evaluate enantioselectivities, product enantiomeric excesses were obtained from $4 \mathrm{~h}$ samples by chiral GC described elsewhere. ${ }^{[17]}$

To assess activities in different organic co-solvents, reactions contained $25 \%(\mathrm{v} / \mathrm{v})$ of co-solvents such as ethanol, methanol, 2-propanol, acetonitrile, dimethylsulfoxide, dimethylformamide. Sampling of duplicate reactions was performed after 4 and $24 \mathrm{~h}$ and analyzed by achiral GC.

For activities with increasing concentrations of substrate and co-solvent 2-propanol, reactions were performed under standard conditions. A constant azide concentration of $40 \mathrm{mM}$ was used with different concentrations of substrate $1(5,10,20,50,100,150$, or $200 \mathrm{mM})$. Sampling and achiral GC analysis were performed after 4 and $24 \mathrm{~h}$. Reactions were performed in duplicates.

\section{Crystallization of HheG wild type and variants at different scales}

Crystallization in $2 \mu$ l scale in 96-well plates

For initial crystallization screening, sitting-drop crystallization was performed in $2 \mu \mathrm{l}$ scale using 96well CrystalQuick SW plates (Greiner Bio-one, Kremsmünster, Austria). Droplets were produced by mixing protein solutions of $18,20,22$, or $24 \mathrm{mg} / \mathrm{ml}$ at a ration of $1: 1$ with crystallization buffer containing 10 mM HEPES (pH 7.0, 7.3, or 7.5) and 2 to 16\% (w/v) PEG4000. Reservoirs for sitting-drop application contained $140 \mu \mathrm{l}$ crystallization buffer. Different conditions were analyzed in triplicates and crystallization success was determined after $72 \mathrm{~h}$ incubation at $8^{\circ} \mathrm{C}$ using microscope SMZ-171-TLED (Moticeurope, Barcelona, Spain). 
Crystallization in $20 \mu$ l scale in petri dishes

To determine crystallization parameters, crystallization was scaled up to $20 \mu \mathrm{l}$. Now, sitting-drop crystallization was performed in $20 \mu \mathrm{l}$ droplets containing optimized protein solution mixed with crystallization buffer (1:1) (Table S2) on cover glass plates. For wild-type HheG, a protein concentration of $32 \mathrm{mg} / \mathrm{ml}$ was used in contrast to $24 \mathrm{mg} / \mathrm{ml}$ for variant HheG D114C. As reservoir, $3 \mathrm{ml}$ crystallization buffer were placed in a separate, smaller petri dish. For $72 \mathrm{~h}$ at $8{ }^{\circ} \mathrm{C}$, droplets (on cover glass) and reservoir (in small petri dish) were placed in a standard petri dish that was sealed with parafilm until microscopic documentation.

Crystallization in $200 \mu \mathrm{l}$ scale in glass vials

For preparation of CLECs, crystallization conditions were scaled up to $200 \mu$ l. Here, precipitation crystallization was performed for $24 \mathrm{~h}$ at $8^{\circ} \mathrm{C}$ in $2 \mathrm{ml}$ glass vials by mixing $100-150 \mu \mathrm{l}$ protein solutions (see above) with 50-100 $\mu$ l crystallization buffer.

To determine the amount of crystallized protein crystals, samples were centrifuged for $3 \mathrm{~min}$ at $400 \mathrm{~g}$ and the amount of crystallized protein was inferred from the remaining protein absorbance at $280 \mathrm{~nm}$ in the supernatant. Crystal sizes were measured using ImageJ software ${ }^{[43]}$ to calculate crystal volumes using the formula for a regular six-sided prism (Equation S1).

\section{Cross-linking of HheG wild type and variant D114C}

Cross-linking in $20 \mu \mathrm{l}$ scale in petri dishes

After $72 \mathrm{~h}$ crystallization, mother liquor was removed from crystals via a paper towel and $20 \mu \mathrm{l}$ crosslinking solution containing $2 \mathrm{mM} \mathrm{BMOE}$ in crystallization buffer were added to collected crystals. After cross-linking for $24 \mathrm{~h}$ at $8{ }^{\circ} \mathrm{C}$, cross-linking mother liquor was removed via paper towel. Then, CLECs were submerged in $5 \mu \mathrm{l} 50 \mathrm{mM}$ Tris. $\mathrm{SO}_{4} \mathrm{pH} 7.0$ and subsequently removed via paper towel. To monitor CLEC stability, CLECs were placed in $20 \mu \mathrm{l} 50 \mathrm{mM}$ Tris. $\mathrm{SO}_{4} \mathrm{pH} 7.0$ and stored for $72 \mathrm{~h}$ at $8{ }^{\circ} \mathrm{C}$ following microscopic inspection.

Cross-linking in $200 \mu$ l scale in glass vials

For the evaluation of CLECs under experimental conditions, cross-linking was scaled up to $200 \mu$ by removing crystallization mother liquor after $24 \mathrm{~h}$ via centrifugation for $3 \mathrm{~min}$ at $400 \mathrm{~g}$. Then collected crystals of wild-type HheG and variant D114C were submerged in $200 \mu \mathrm{l}$ cross-linking solution containing either $5 \%(\mathrm{v} / \mathrm{v})$ glutaraldehyde or $2 \mathrm{mM} \mathrm{BMOE}$ in crystallization buffer for $24 \mathrm{~h}$ at $8{ }^{\circ} \mathrm{C}$. Cross-linking mother liquor was removed from CLECs by centrifugation and rinsing with $200 \mu 50 \mathrm{mM}$ Tris. $\mathrm{SO}_{4}, \mathrm{pH}$ 7.0. For the evaluation of CLEC thermal stabilities, different CLECs were generated by 
varying cross-linking parameters such as the concentration of $\operatorname{BMOE}(0.5,1,2,5,10$, or $20 \mathrm{mM})$ and the cross-linking time $(3,6,18,24,48$, or $72 \mathrm{~h})$.

\section{Temperature and $\mathrm{pH}$ profiles}

To evaluate thermal stabilities, reactions of $1 \mathrm{ml}$ were performed under standard conditions at different temperatures $\left(10,20,25,30,35,40,45,50\right.$, and $\left.60^{\circ} \mathrm{C}\right)$. Samples were taken after $2 \mathrm{~h}$ and subsequently analyzed as described above. Maximum conversion was set to $100 \%$ relative activity and reactions were performed in duplicate.

Thermal shift assays were performed using a QuantStudio 1 Real-Time-PCR system (Thermo Fisher Scientific) in $50 \mu \mathrm{l}$ in MicroAmp Optical 96-Well Reaction plates (Thermo Fisher Scientific) containing 5-20 $\mu$ g protein or CLEC $(5 \mu \mathrm{l}), 5 \mu \mathrm{l}$ 50x concentrated SYPRO orange as fluorescent dye (Thermo Fisher Scientific), and $40 \mu \mathrm{l} \mathrm{TE}$ buffer. Fluorescence (excitation: $580 \pm 10 \mathrm{~nm}$, emission: $623 \pm 14 \mathrm{~nm}$ ) was monitored after increasing the temperature in $0.5^{\circ} \mathrm{C}$ steps from 10 to $90^{\circ} \mathrm{C}$. The temperature at which the maximum fluorescence change was observed, representing the melting temperature, and which was calculated with the Protein Thermal Shift software (version 1.4, Thermo Fisher Scientific).

For obtaining melting temperatures with different co-solvents, thermal shift assays contained $10 \%$ $(\mathrm{v} / \mathrm{v})$ of following solvents: ethanol, methanol, 2-propanol, acetonitrile, dimethylsulfoxide, dimethylformamide.

For the determination of melting temperatures at other $\mathrm{pH}$ values, $40 \mu \mathrm{l}$ of TE buffer were replaced by buffers siuch as $50 \mathrm{mM}$ citrate $\mathrm{pH}$ 4-6, $50 \mathrm{mM}$ phosphate $\mathrm{pH}$ 6-7, $50 \mathrm{mM}$ Tris.5O $\mathrm{SO}_{4} \mathrm{pH}$ 7-8.5, or glycine- $\mathrm{NaOH}$ pH 8.5-11.

Using the same selection of buffers, activity profiles for different $\mathrm{pH}$ values were collected as described above with sampling after $2 \mathrm{~h}$ and achiral GC analysis to determine relative activities.

To determine thermal inactivation ( $\left.T_{50}\right)$ values of soluble HheG D114C and CLECs, $100 \mu \mathrm{g}$ of biocatalyst was first incubated for $30 \mathrm{~min}$ at different temperatures $(10,20,30,32.9,35.7,38.6,41.4,44.3,47.1$, 50,60 , or $70^{\circ} \mathrm{C}$ ). Afterwards, residual activity was determined in the conversion of cyclohexene oxide (1) with azide using standard reaction conditions $\left(20 \mathrm{mM} 1\right.$ and $40 \mathrm{mM}$ azide in $50 \mathrm{mM}$ Tris. $\mathrm{SO}_{4}, \mathrm{pH} 7.0$ at $22^{\circ} \mathrm{C}$ and $900 \mathrm{rpm}$ for $2 \mathrm{~h}$ ). Samples were analyzed by achiral GC analysis (Table S7).

\section{Determination of half-life times}

Half-life times $\left(t_{1 / 2}\right)$ of soluble HheG D114C and D114C CLECs at $22{ }^{\circ} \mathrm{C}$ were obtained based on the determination of deactivation rate constants $\left(k_{d}\right)$. Deactivation rate constants at 30,32 and $34{ }^{\circ} \mathrm{C}$ for soluble enzyme, and $36,38,40^{\circ} \mathrm{C}$ for CLECs were determined by incubating the enzyme preparations at respective temperatures (T). After $0,15,30,60,90,120,180$ and 240 min of incubation, samples were taken for reactions containing $50 \mu \mathrm{g}$ soluble enzyme or $100 \mu \mathrm{g}$ CLECs, $20 \mathrm{mM}$ cyclohexene oxide 
(1) and $40 \mathrm{mM}$ azide at $22^{\circ} \mathrm{C}$ and $900 \mathrm{rpm}$ to determine conversions after $30 \mathrm{~min}$. As the performed reaction of cyclohexene oxide (1) with azide can be described by a pseudo-first order reaction, the natural logarithm of conversion was plotted against time to derive the corresponding deactivation rate constant at a given temperature from the respective slope after linear regression. Plotting $\ln \left(\mathrm{k}_{\mathrm{d}} / \mathrm{T}\right)$ against $1 / \mathrm{T}$ in an Eyring plot (Figure S12) enabled determination of respective deactivation rate constants of both enzyme preparations at $22^{\circ} \mathrm{C}$ based on the Eyring equation. ${ }^{[38]}$ Corresponding deactivation energies $\left(E_{d}\right)$ and half-life times $\left(t_{1 / 2}\right)$ were calculated using Equations $S 4$ and $S 5$, respectively. ${ }^{[38,44]}$

\section{Reuseability}

For the determination of D114C CLEC reuseability, consecutive batch reactions were performed in $1 \mathrm{ml}$ as described in activity section with $100 \mu \mathrm{g}$ CLECs. After $24 \mathrm{~h}$, samples were taken for achiral and chiral GC analysis (Table S7). Then, remaining reaction mixture was centrifuged for $3 \mathrm{~min}$ at $400 \mathrm{~g}$ and new reaction medium was added. This procedure was repeated for 21 days with daily sampling in quintuplicates. Similarly, duplicate reactions of $10 \mathrm{mM}$ phenylglycidylether (3), styrene oxide (5), phenylpropylene oxide (7), or limonene oxide (9) with $20 \mathrm{mM}$ azide and $200 \mu \mathrm{g}$ CLECs were carried out in $50 \mathrm{mM}$ Tris. $\mathrm{SO}_{4} \mathrm{pH} 7.0$ for $24 \mathrm{~h}$ at $22{ }^{\circ} \mathrm{C}(900 \mathrm{rpm})$. For five days, daily samples were analyzed by achiral GC and CLECs were reused as for epoxide 1.

\section{Crystallization for structure determination}

Crystallization was achieved in 96-well sitting-drop vapor diffusion plates at $277 \mathrm{~K}$ using $200 \mathrm{~nL}$ of protein solution at a concentration of $23.4 \mathrm{mg} / \mathrm{mL}$ mixed with the same volume of precipitant. Plate set-up was performed with a Crystal Gryphon robot (Art Robbins Instruments, Sunnyvale, USA). Crystals were obtained after $24 \mathrm{~h}$. For crosslinking crystals were soaked by adding $0.1 \mu \mathrm{L}$ of a $0.88 \mu \mathrm{g} / \mu \mathrm{L}$ BMOE-solution to the crystallization drop followed by $24 \mathrm{~h}$ incubation at $277 \mathrm{~K}$. The harvested crystals were cryoprotected in reservoir solution supplemented with $10 \%(\mathrm{v} / \mathrm{v})(2 R, 3 R)-(-)-2,3$-butanediol and flash cooled in liquid nitrogen.

\section{Diffraction data collection and structure determination}

Diffraction data were collected with crystals grown in 46 mM HEPES pH 7.34, $5.33 \%$ (w/v) PEG 8000 on beamline P11 (PETRA III synchrotron, DESY, Hamburg, Germany). Data indexing, integration, scaling and reduction was done using the autoPROC pipeline. ${ }^{[45]}$ Phasing was achieved by molecular replacement with Phaser ${ }^{[46]}$ using the HheG wildtype structure (PDB ID: 5030) as a model. An initial model was obtained using phenix.refine of the phenix software suite ${ }^{[4]]}$ and completed by manual 
adjustments with $\mathrm{Coot}^{[48]}$. Alternating rounds of manual optimization and phenix.refine were used for further refinement. Data collection and refinement statistics are listed in Table S3.

\section{Acknowledgement}

We are grateful to the staff of beamline P11 at the PETRAIll synchrotron (DESY campus Hamburg, Germany) for provision of their facilities and assistance in using the beamline. Peer Lukat is especially acknowledged for help with data collection. Additionally, we thank Dr. Felix Kaspar and Dr. Marcus Schallmey for helpful advice on the manuscript.

Financial support of M.S. and S.H. by the German Research Foundation (DFG) within the Priority Programme 1934 (DiSPBiotech) and the Research Training Group 2223 (PROCOMPAS), respectively, is gratefully acknowledged.

\section{References}

[1] A. Schallmey, M. Schallmey, Appl. Microbiol. Biotechnol. 2016, 100, 7827-7839.

[2] G. Hasnaoui-Dijoux, M. M. Elenkov, J. H. L. Spelberg, B. Hauer, D. B. Janssen, ChemBioChem 2008, 9, 1048-1051.

[3] M. M. Heravi, V. Zadsirjan, B. Farajpour, RSC Adv. 2016, 6, 30498-30551.

[4] M. M. Elenkov, H. W. Hoeffken, L. Tang, B. Hauer, D. B. Janssen, Adv. Synth. Catal. 2007, 349, 2279-2285.

[5] J. H. Lutje Spelberg, J. E. T. van Hylckama Vlieg, T. Bosma, R. M. Kellogg, D. B. Janssen, Tetrahedron Asymmetry 1999, 10, 2863-2870.

[6] M. M. Elenkov, I. Primožič, T. Hrenar, A. Smolko, I. Dokli, B. Salopek-Sondi, L. Tang, Org. Biomol. Chem. 2012, 10, 5063-5072.

[7] M. Schallmey, J. Koopmeiners, E. Wells, R. Wardenga, A. Schallmey, Appl. Environ. Microbiol. 2014, 80, 7303-7315.

[8] J. Koopmeiners, B. Halmschlag, M. Schallmey, A. Schallmey, Appl. Microbiol. Biotechnol. 2016, $100,7517-7527$.

[9] J. Koopmeiners, C. Diederich, J. Solarczek, H. Voß, J. Mayer, W. Blankenfeldt, A. Schallmey, ACS Catal. 2017, 7, 6877-6886.

[10] E. Calderini, J. Wessel, P. Süss, P. Schrepfer, R. Wardenga, A. Schallmey, ChemCatChem 2019, 11, 2099-2106.

[11] M. An, W. Liu, X. Zhou, R. Ma, H. Wang, B. Cui, W. Han, N. Wan, Y. Chen, RSC Adv. 2019, 9, 16418-16422. 
[12] R. M. de Jong, K. H. Kalk, L. Tang, D. B. Janssen, B. W. Dijkstra, J. Bacteriol. 2006, 188, 40514056.

[13] EMBO J. 2003, 22, 4933-4944.

[14] F. Watanabe, F. Yu, A. Ohtaki, Y. Yamanaka, K. Noguchi, M. Yohda, M. Odaka, Proteins 2015, 83, 2230-2239.

[15] J. Wessel, G. Petrillo, M. Estevez-Gay, S. Bosch, M. Seeger, W. P. Dijkman, J. Iglesias-Fernández, A. Hidalgo, I. Uson, S. Osuna, A. Schallmey, FEBS J. 2021, 288, 4683-4701.

[16] A. Sharma, J. Agarwal, R. K. Peddinti, Org. Biomol. Chem. 2017, 15, 1913-1920.

[17] J. Solarczek, T. Klünemann, F. Brandt, P. Schrepfer, M. Wolter, C. R. Jacob, W. Blankenfeldt, A. Schallmey, Sci. Rep. 2019, 9, 1-10.

[18] C. Silva, M. Martins, S. Jing, J. Fu, A. Cavaco-Paulo, Crit. Rev. Biotechnol. 2018, 38, 335-350.

[19] R. A. Sheldon, S. van Pelt, Chem. Soc. Rev. 2013, 42, 6223-6235.

[20] H. Noritomi, K. Koyama, S. Kato, K. Nagahama, Biotechnol. Tech. 1998, 12, 467-469.

[21] N. Khalaf, C. P. Govardhan, J. J. Lalonde, R. A. Persichetti, Y.-F. Wang, A. L. Margolin, J. Am. Chem. Soc. 1996, 118, 5494-5495.

[22] J. D. Vaghjiani, T. S. Lee, G. J. Lye, M. K. Turner, Biocatal. Biotransformation 2000, 18, 151-175.

[23] I. Migneault, C. Dartiguenave, M. J. Bertrand, K. C. Waldron, BioTechniques 2004, 37, 790-802.

[24] M. Kubiak, M. Staar, I. Kampen, A. Schallmey, C. Schilde, Crystals 2021, 11, 718.

[25] B. Smejkal, B. Helk, J.-M. Rondeau, S. Anton, A. Wilke, P. Scheyerer, J. Fries, D. Hekmat, D. Weuster-Botz, Biotechnol. Bioeng. 2013, 110, 1956-1963.

[26] B. Jiménez-García, K. Elez, P. I. Koukos, A. M. Bonvin, A. Vangone, Bioinformatics 2019, 35, 4821-4823.

[27] J. R. Auclair, K. J. Boggio, G. A. Petsko, D. Ringe, J. N. Agar, Proc. Natl. Acad. Sci. 2010, 107, 21394-21399.

[28] M. Kubiak, J. Solarczek, I. Kampen, A. Schallmey, A. Kwade, C. Schilde, Cryst. Growth Des. 2018, $18,5885-5895$.

[29] Z. S. Derewenda, Structure 2004, 12, 529-535.

[30] D. R. Cooper, T. Boczek, K. Grelewska, M. Pinkowska, M. Sikorska, M. Zawadzki, Z. Derewenda, Acta Crystallogr. D Biol. Crystallogr. 2007, 63, 636-645.

[31] E. M. Westbrook, P. B. Sigler, J. Biol. Chem. 1984, 259, 9090-9095.

[32] J. J. Lalonde, M. Navia, A. L. Margolin, in Methods Enzymol., Academic Press, 1997, pp. 443464.

[33] D. W. Heinz, B. W. Matthews, Protein Eng. Des. Sel. 1994, 7, 301-307.

[34] E. Krissinel, K. Henrick, J. Mol. Biol. 2007, 372, 774-797.

[35] J. Jegan Roy, T. Emilia Abraham, Chem. Rev. 2004, 104, 3705-3722. 
[36] P. A. Fitzpatrick, A. C. Steinmetz, D. Ringe, A. M. Klibanov, Proc. Natl. Acad. Sci. 1993, 90, 86538657.

[37] Z. Wang, G. Zhu, Q. Huang, M. Qian, M. Shao, Y. Jia, Y. Tang, Biochim. Biophys. Acta BBA Protein Struct. Mol. Enzymol. 1998, 1384, 335-344.

[38] Henry. Eyring, A. E. Stearn, Chem. Rev. 1939, 24, 253-270.

[39] S. B. Sobolov, M. D. Leonida, A. Bartoszko-Malik, K. I. Voivodov, F. McKinney, J. Kim, A. J. Fry, J. Org. Chem. 1996, 61, 2125-2128.

[40] J. J. Roy, T. E. Abraham, J. Mol. Catal. B Enzym. 2006, 38, 31-36.

[41] Q. Liao, X. Du, W. Jiang, Y. Tong, Z. Zhao, R. Fang, J. Feng, L. Tang, J. Biotechnol. 2018, 272-273, 48-55.

[42] E. Gasteiger, C. Hoogland, A. Gattiker, S. Duvaud, M. R. Wilkins, R. D. Appel, A. Bairoch, in Proteomics Protoc. Handb. (Ed.: J.M. Walker), Humana Press, Totowa, NJ, 2005, pp. 571-607.

[43] WS. RASBAND, http://imagej.nih.gov/ij/ 2011.

[44] K. S. Siddiqui, A. M. Shemsi, M. A. Anwar, M. H. Rashid, M. I. Rajoka, Enzyme Microb. Technol. 1999, 24, 599-608.

[45] C. Vonrhein, C. Flensburg, P. Keller, A. Sharff, O. Smart, W. Paciorek, T. Womack, G. Bricogne, Acta Crystallogr. D Biol. Crystallogr. 2011, 67, 293-302.

[46] A. J. McCoy, R. W. Grosse-Kunstleve, P. D. Adams, M. D. Winn, L. C. Storoni, R. J. Read, J. Appl. Crystallogr. 2007, 40, 658-674.

[47] D. Liebschner, P. V. Afonine, M. L. Baker, G. Bunkoczi, V. B. Chen, T. I. Croll, B. Hintze, L. W. Hung, S. Jain, A. J. McCoy, N. W. Moriarty, R. D. Oeffner, B. K. Poon, M. G. Prisant, R. J. Read, J. S. Richardson, D. C. Richardson, M. D. Sammito, O. V. Sobolev, D. H. Stockwell, T. C. Terwilliger, A. G. Urzhumtsev, L. L. Videau, C. J. Williams, P. D. Adams, Acta Crystallogr. Sect. Struct. Biol. 2019, 75, 861-877.

[48] P. Emsley, B. Lohkamp, W. G. Scott, K. Cowtan, Acta Crystallogr. D Biol. Crystallogr. 2010, 66, 486-501. 